\title{
Striking Variations in Corticosteroid Modulation of Long- Term Potentiation along the Septotemporal Axis of the Hippocampus
}

\author{
Nicola Maggio and Menahem Segal \\ Department of Neurobiology, The Weizmann Institute, 76100 Rehovot, Israel
}

The ability to express long-term potentiation (LTP) of reactivity to afferent stimulation along the septotemporal axis was explored in transverse rat hippocampal slices. The ventral pole of the hippocampus $(\mathrm{VH})$ was found to be much impaired in ability to express LTP compared with the rest of the hippocampus. An exposure to acute stress before the rat was killed reversed this trend, and slices from VH now expressed a large LTP, whereas in the rest of the hippocampus, it was much suppressed. The enhanced LTP in VH was mediated by activation of a mineralocorticoid receptor (MR), whereas the suppressed LTP was mediated by activation of a glucocorticoid receptor, and indeed selective agonists of the respective steroid receptors mimicked the effects of stress, whereas selective antagonists blocked them. The MR-enhanced LTP in VH was not mediated by activation of the NMDA receptor but by enhancement of voltage-gated calcium channels. Because the VH has an unique efferent system to the hypothalamus, these results indicate that stress may activate this system while suppressing the ability of the rest of the hippocampus to express plastic properties under stressful conditions.

Key words: hippocampus; slices; LTP; corticosteroids; stress; calcium

\section{Introduction}

Recent findings propose that a functional differentiation exists along the septotemporal axis of the hippocampus, such that the traditional assignment of cognitive functions to this structure is, in fact, associated mainly with its dorsal sector (Colombo et al., 1998; Moser and Moser, 1998; Strange et al., 1999; Pothuizen et al., 2004). In particular, it has been demonstrated that only lesions of the dorsal hippocampus (DH) cause a deficit in spatial memory performance (Bannerman et al., 1999; Pothuizen et al., 2004). In contrast, ventral hippocampal (VH) damage causes behavioral disinhibition and reduced anxiety (Kjelstrup et al., 2002; Bannerman et al., 2003, 2004; Trivedi and Coover, 2004) but not decreased memory functions. Interestingly, the ventral hippocampus, more than the dorsal sector, is involved in the development of affective disorders (Degroot and Treit, 2004). These studies have demonstrated that the dorsal hippocampus encodes spatial memory, whereas the ventral sector processes information related to the motivational and homeostatic state of the animal (Moser and Moser, 1998). In support of this hypothesis, it was shown, both in vivo (Maruki et al., 2001) and in vitro (Papatheodoropoulos and Kostopoulos, 2000; Colgin et al., 2004; Maggio and Segal, 2007), that the ability to evoke short- and long-term plasticity differs between $\mathrm{DH}$ and VH. Specifically, in VH, the

\footnotetext{
Received Jan. 15, 2007; revised April 11, 2007; accepted April 11, 2007.

We thank S. Sapoznik and E. Korkotian for help with the preparation of the figures, A. Vlachos for critical discussions, and A. Avital for statistical advice.

Correspondence should be addressed to Menahem Segal at the above address. E-mail: menahem.segal@weizmann.ac.il.

DOI:10.1523/JNEUROSCI.0155-07.2007

Copyright $\odot 2007$ Society for Neuroscience $\quad$ 0270-6474/07/275757-09\$15.00/0
}

magnitude of long-term potentiation (LTP), a cellular model of learning and memory (Bliss and Collingridge, 1993), is significantly smaller than LTP elicited in the DH (Maggio and Segal, 2007).

Stress is a biologically significant factor shown to influence hippocampal synaptic plasticity and cognitive functions (Kim and Yoon, 1998; Garcia, 2002; Kim et al., 2006). Specifically, LTP is impaired in the dentate gyrus in vivo, after exposure to stress (Korz and Frey, 2003; Ahmed et al., 2006). In addition, application of corticosterone, the major stress hormone in rodents, to CA1 in hippocampal slices has been shown to produce similar results (Krugers et al., 2005; Wiegert et al., 2005). However, recent studies indicate that the effects of corticosteroids on LTP is more complicated than originally thought (Joels, 2006). Specifically, after exposure to acute swim stress, the activation of mineralocorticoid receptors (MRs) produced an enhancement of LTP, whereas an LTP impairment was found after activation of glucocorticoid receptors (GRs) before the stressful experience (Avital et al., 2006). These studies suggest that MRs and GRs assume opposite roles in regulation of synaptic plasticity after an acute exposure to stressors.

Using hippocampal slices, we explored the differential ability to evoke LTP along the septotemporal axis of hippocampal CA1. Furthermore, we examined whether LTP could be differentially modulated in the $\mathrm{DH}$ versus $\mathrm{VH}$ after an exposure to acute stress or to direct corticosteroid application. We demonstrate that the lack of LTP is a specific property of the VH sector and that stress and corticosterone enhance LTP in the VH through a mechanism that requires $\mathrm{MR}$ and activation of voltage-gated calcium channels (VGCCs). 


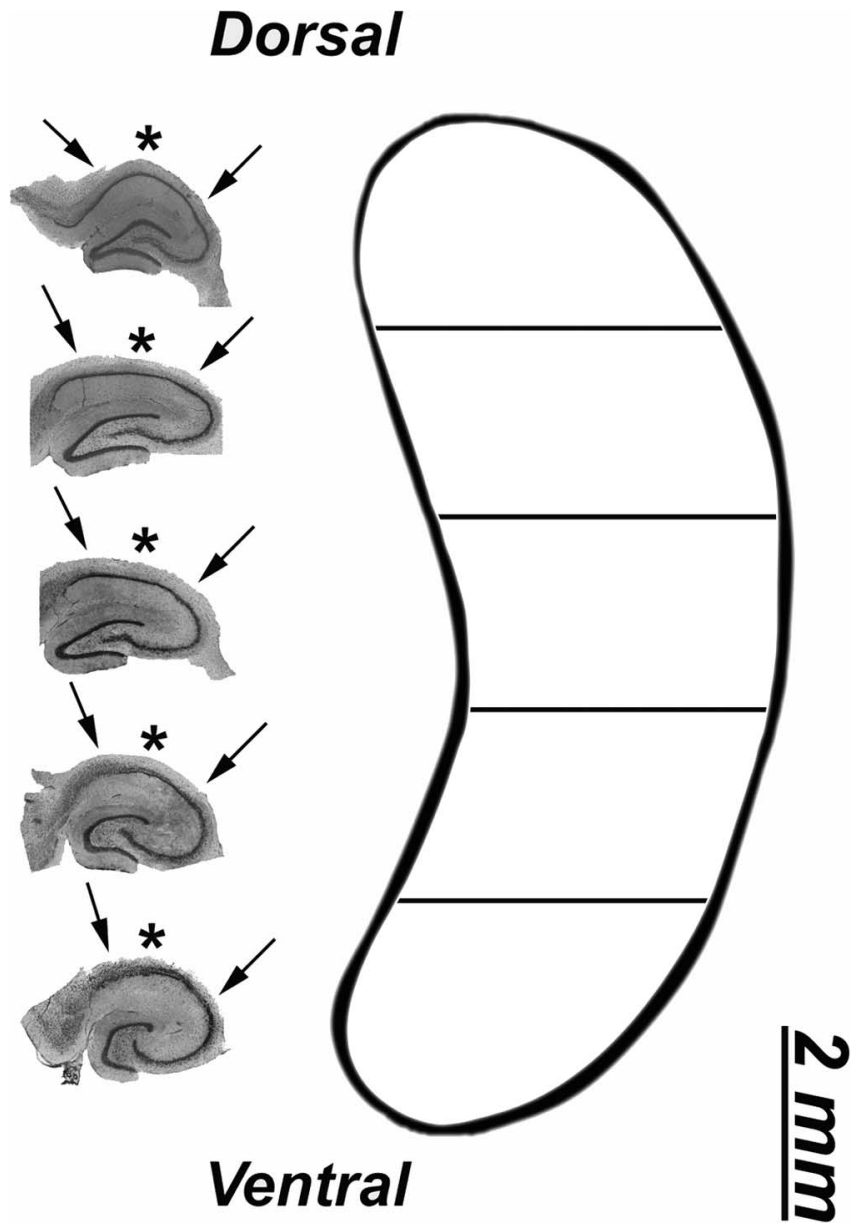

Figure 1. Slicing procedure. The hippocampus was divided along its septotemporal axis into five sectors of $2 \mathrm{~mm}$ each. Transverse slices $(350 \mu \mathrm{m})$ were collected from each sector for recordings. Nissl-stained representative sections per sector are shown on the left. Arrows indicate stimulating electrodes. Asterisk indicates placement of recording pipette.

\section{Materials and Methods}

The following drugs (at final concentrations) were used: corticosterone (1 $\mu \mathrm{M})$, spironolactone (500 nM), mifepristone (RU38486; $500 \mathrm{nM}$ ), aldosterone (10 nM), dexamethasone (100 nM), APV (50 $\mu \mathrm{M})$, DNQX (10 $\mu \mathrm{M})$, glycine $(10 \mu \mathrm{M})$, nifedipine $(10 \mu \mathrm{M})$, and $2^{\prime}$ amino-3'-methoxyflavone (PD98059; $1 \mu \mathrm{M})$. All drugs were purchased from Sigma (St. Louis, MO). Pharmaceuticals were added to the perfusion medium with special care to prevent changes in temperature, $\mathrm{pH}$, flow rate, or degree of oxygenation of the artificial CSF (ACSF).

Stress procedure. Experiments were conducted according to institutional rules and regulations, and we obtained a local Institutional Animal Care and Use Committee permission. The acute swim stress (ASS) protocol consisted of exposing a naive Wistar rat to a forced swim test. Stress exposure was always done at 9:00 A.M., when the plasma corticosterone levels are low (Finn et al., 2003, Krugers et al., 2005). Briefly, individual rats were placed for $15 \mathrm{~min}$ in a circular water tank (diameter, $0.5 \mathrm{~m}$; height, $0.5 \mathrm{~m}$ ). Water depth was $40 \mathrm{~cm}$, and temperature was maintained at $23 \pm 1^{\circ} \mathrm{C}$. After exposure to ASS, rats were allowed to rest for $1 \mathrm{~h}$ before they were killed.

Slice preparation. Male Wistar rats (10-12 weeks of age) were rapidly decapitated, the hippocampus was removed, and $350 \mu \mathrm{m}$ slices were prepared using a McIlwain tissue slicer. Specifically, the hippocampus was divided into five sectors of $2 \mathrm{~mm}$ each. Transverse slices were collected from all of the hippocampal sectors; however, the last $350 \mu \mathrm{m}$ slices at each of the two extremities were discarded. All studies of comparison between dorsal and ventral hippocampus were performed on slices derived from the same hippocampus under the same experimental
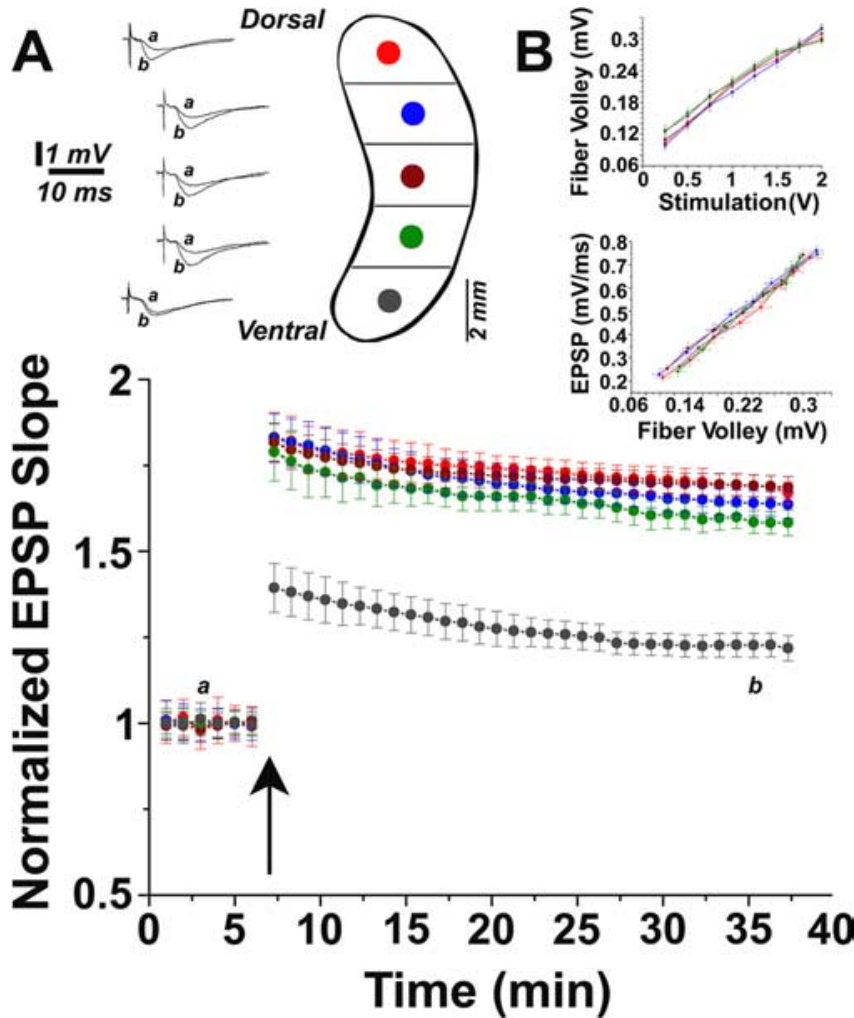

Figure 2. LTP is specifically impaired in the ventral sector of the hippocampus. $A, \operatorname{In} V H$ slices, a tetanic stimulation induces lower-magnitude LTP than in slices from other hippocampal sectors. Averaged EPSP slopes are plotted versus time (bottom). Representative traces at indicated times are shown on top. The arrow indicates the time of HFS. $\boldsymbol{B}$, Input- output curves do not show any difference between the different hippocampal sectors.

conditions. To obtain the same slice conditions, the plate supporting the structure was rotated to cut both regions perpendicularly to the longitudinal axis of the hippocampus.

Electrophysiology. Slices were incubated for $1.5 \mathrm{~h}$ in a humidified, carbogenated $\left(5 \% \mathrm{CO}_{2}\right.$ and $\left.95 \% \mathrm{O}_{2}\right)$ gas atmosphere at $33 \pm 1{ }^{\circ} \mathrm{C}$ and were perfused with ACSF [containing (in mM) $124 \mathrm{NaCl}, 2 \mathrm{KCl}, 26 \mathrm{NaHCO}_{3}$, $1.24 \mathrm{KH}_{2} \mathrm{PO}_{4}, 2.5 \mathrm{CaCl}_{2}, 2 \mathrm{MgSO}_{4}$, and 10 glucose, $\left.\mathrm{pH} 7.4\right]$ in a standard interface chamber. Recordings were made with a glass pipette containing $0.75 \mathrm{M} \mathrm{NaCl}(4 \mathrm{M} \Omega)$ placed in the stratum radiatum CA1. Stimulation was evoked using a Master 8 pulse stimulator (A.M.P.I., Jerusalem, Israel) and was delivered through two sets of bipolar nichrome electrodes placed on either side of the recording electrode such that two independent stimulation channels were used for each slice. LTP was induced by high-frequency stimulation (HFS) consisting of 100 pulses at twice the test intensity, delivered at a frequency of $100 \mathrm{~Hz}(100 \mathrm{~Hz}, 1 \mathrm{~s})$. Before applying the tetanic stimulation, baseline values were recorded at a frequency of $0.033 \mathrm{~Hz}$. Responses were digitized at $5 \mathrm{kHz}$ and stored on a computer. Off-line analysis and data acquisition were performed using the LTP Program (Anderson and Collingridge, 2001).

All numerical data are expressed as mean \pm SEM, and EPSP slope changes after tetanic stimulation were calculated with respect to baseline. There were no systematic differences in the magnitudes of the baseline responses in the different conditions. All values reported refer to $30 \mathrm{~min}$ after tetanic stimulation. Unless otherwise indicated, statistical evaluation was performed by applying a Student's $t$ test for paired or unpaired data, as the case may be (Origin 6.0). $p$ values of $<0.05$ were considered a significant difference between means.

Histology. Slices from all of the hippocampal sectors were fixed in $4 \%$ paraformaldehyde in PBS, $\mathrm{pH}$ 7.4, for $1 \mathrm{~h}$ and then soaked in a solution containing $30 \%$ sucrose $/ 2 \%$ paraformaldehyde and stored at $4^{\circ} \mathrm{C}$. Sections $(30 \mu \mathrm{m})$ were cut using a slide microtome and stained with cresyl violet. 

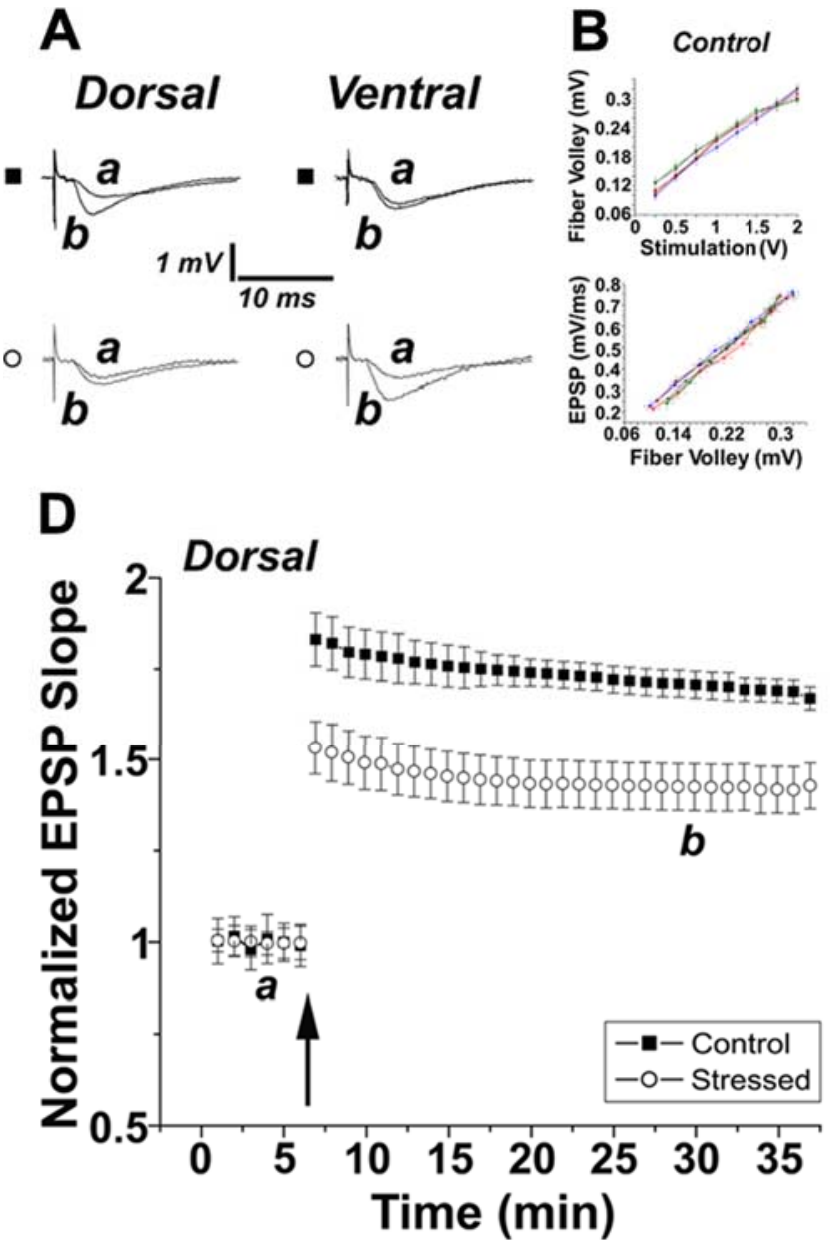
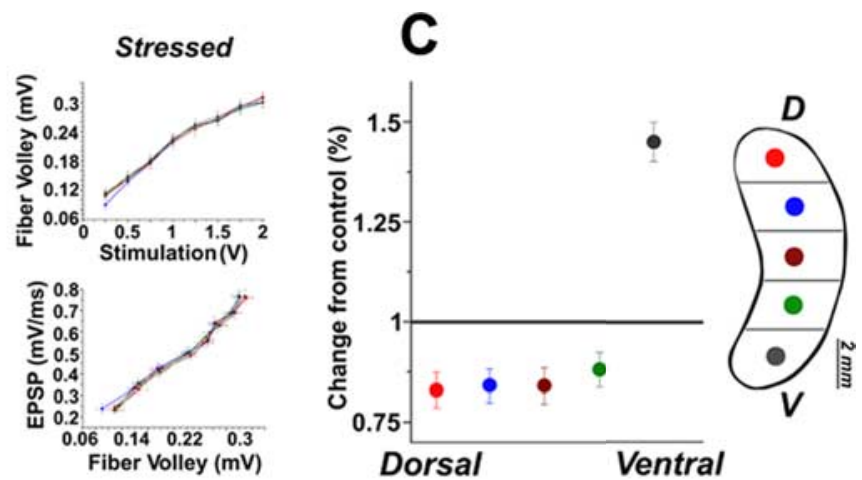

$\mathbf{E}$

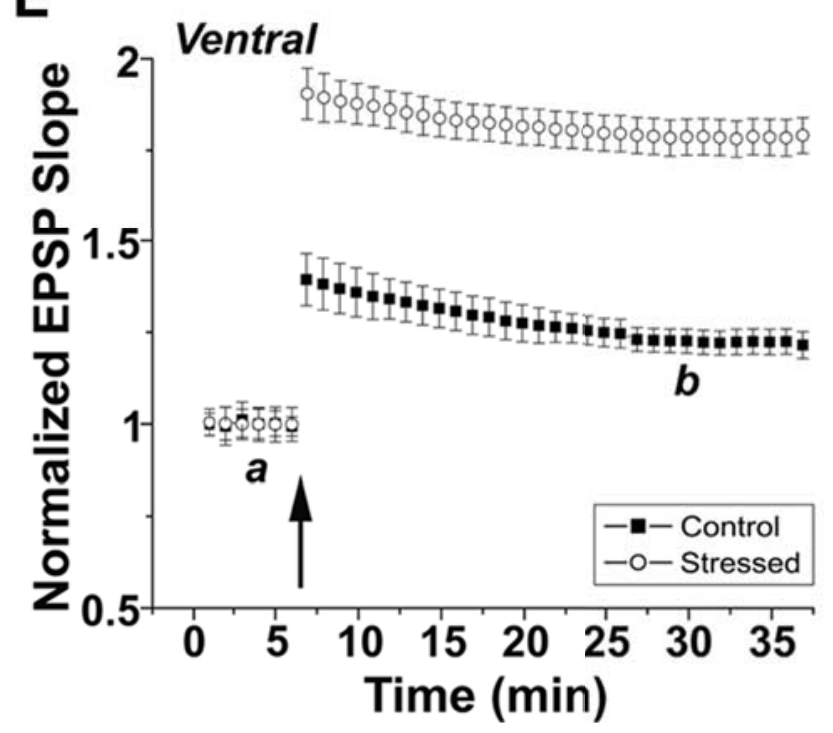

Figure 3. Behavioral stress enhances LTP in VH, whereas it suppresses LTP in DH. $\boldsymbol{A}$, Representative traces at indicated times showing the differences in LTP between control and stressed animals in DH and VH. $\boldsymbol{B}$, Input- output curves do not differ between the groups, along the septotemporal axis of the hippocampus. $\boldsymbol{C}$, Stress enhances LTP only in the VH. $\boldsymbol{D}$, In DH slices, tetanic stimulation evoked a lower-magnitude LTP in the stressed group (open circles) than in the control (filled squares). $\boldsymbol{E}$, In VH, stress enhances LTP (open circles) compared with the control group (filled squares). Averaged EPSP slopes are plotted versus time. The arrows indicate the time of HFS.

\section{Results}

LTP is lower in CA1 of the VH

Ventral hippocampus CA1 has been shown to express a lowermagnitude LTP (Papatheodoropoulos and Kostopoulos, 2000; Maruki et al., 2001; Colgin et al., 2004; Maggio and Segal, 2007). However, whether this is a genuine property of only the ventral sector or whether there is a gradient between the two ends of the structure is still an open question. We addressed this issue by recording from slices from five sectors along the septotemporal axis (Fig. 1). To minimize the time factor after slicing, slices from $\mathrm{DH}$ and $\mathrm{VH}$ were alternated randomly between experiments. In addition, the recordings were made by stimulating two parallel pathways in the same slice. The experiment consisted of delivering an HFS after 5 min of baseline recordings after the establishment of an input-output curve. Delivery of HFS caused a large potentiation of synaptic transmission in four of five hippocampal sectors (Fig. $2 \mathrm{~A}$ ). Specifically, the amount of potentiation was not different (after $30 \mathrm{~min}$, red, $1.66 \pm 0.031$; blue, $1.63 \pm 0.039$; brown, $1.68 \pm 0.031$; green, $1.58 \pm 0.037 ; n=10$ ) among these areas. However in the ventral-most sector, a significantly lower amount of potentiation was recorded (gray, $1.21 \pm 0.036$; $p<$ $0.001 ; n=10$ ). Specifically, the magnitude of potentiation detected in the $\mathrm{VH}$ was comparable with the one previously reported (Maggio and Segal, 2007). Interestingly, the input-output relationship did not differ across all of the hippocampal sectors (Fig. $2 B$ ). These experiments suggest that the $\mathrm{VH}$ is unique in its lower ability to express LTP.

Stress has a differential effect on the ability to induce LTP in $\mathrm{DH}$ and $\mathrm{VH}$

Stress has been shown recently to reduce LTP (Alfarez et al., 2002; Yang et al., 2004; Krugers et al., 2005; Wiegert et al., 2005) in a steroid receptor-specific manner (Avital et al., 2006). Because lesion studies hint to a specific role of the ventral hippocampus in regulation of anxiety (Kjelstrup et al., 2002), we examined the possible effect of stress on LTP in the VH. Rats were exposed to an ASS, followed by recording from their hippocampal slices. As described previously (Yang et al., 2004), exposure to stress evoked a lower-magnitude LTP in the DH than in control slices (1.42 \pm 0.064 compared with $1.69 \pm 0.032$ in controls; $p<0.001$; $n=10$ ) (Fig. 3C). Surprisingly, in VH slices of the stressed animals, an LTP higher than that of controls could be evoked $(1.78 \pm 0.049$ compared with $1.22 \pm 0.034$ of the controls; $p<$ $0.001 ; n=10$ ) (Fig. $3 E$ ). This effect was specific for the VH slices as LTP decreased by a similar proportion in all of the other hippocampal areas (Fig. 3C). Interestingly, input-output relationships were not different in the rats that underwent the stressful experience compared with controls (Fig. $3 B$ ). These experiments 
demonstrate that stress affects LTP differently along the septotemporal axis of the hippocampus.

\section{Corticosterone mimics the effects of} the stress

Corticosterone is considered to be the major hormone mediating the effects of stress (Joels, 2006). To investigate the mechanisms affected by stress that exert contrasting actions on LTP in $\mathrm{DH}$ versus $\mathrm{VH}$, we exposed slices to $1 \mu \mathrm{M}$ corticosterone before HFS. These experiments were conducted using two parallel pathways so as to allow comparison of the effects of drug application in the same slice. To mimic the resting situation after the stress protocol, the corticosterone exposure lasted $1 \mathrm{~h}$. After 10 min of baseline, delivery of HFS in DH slices evoked a full-magnitude LTP (at $30 \mathrm{~min}$ from the onset, $1.65 \pm 0.039)$. Ten minutes after the HFS, $1 \mu \mathrm{M}$ corticosterone was washed in. One hour later, a second HFS was delivered to the unpotentiated pathway. This stimulation produced a significantly lower LTP (at $30 \mathrm{~min}$ from the onset, $1.36 \pm 0.08 ; p<0.001 ; n=9$ ) (Fig. $4 A$ ), which was comparable with the one induced in the stressed animals. Corticosterone treatment did not affect the input-output response (Fig. 4B). Surprisingly, when the same corticosterone treatment was applied to slices from the $\mathrm{VH}$, an HFS produced a higher-magnitude LTP than the control pathway (at $30 \mathrm{~min}$ from the onset, $1.61 \pm 0.061$ and $1.14 \pm$ 0.046 , respectively; $p<0.001 ; n=9$ ) (Fig. $4 C)$. Also in this case, the corticosterone treatment did not affect input-output relations (Fig. 4D). Additional experiments using a lower concentration of corticosterone (30 nM) (supplemental Fig. 1, available at www.jneurosci.org as supplemental material) demonstrated that a low concentration of corticosterone can also produce the enhancement of LTP. These experiments demonstrate that corticosterone affects differently LTP in DH versus VH and suggest that it could mediate the differential effect of stress in the two regions.

\section{GR and MR differentially regulate LTP} in dorsal versus ventral hippocampus Corticosterone has been proposed to affect LTP differentially by the activation of its two types of receptors; MRs enhance LTP, whereas GRs inhibit LTP in vivo (Avital et al., 2006) and in vitro (Wiegert et al., 2005). To test the hypothesis that corticosterone could mediate its differential effect in DH and VH by specifically activating a subtype of steroid receptor, experiments were conducted using specific MR and GR agonists and antagonists. The results with GR and MR antagonists in dorsal hippocampus are summarized in Figure 5. Briefly, after 10 min of baseline, HFS HFS.
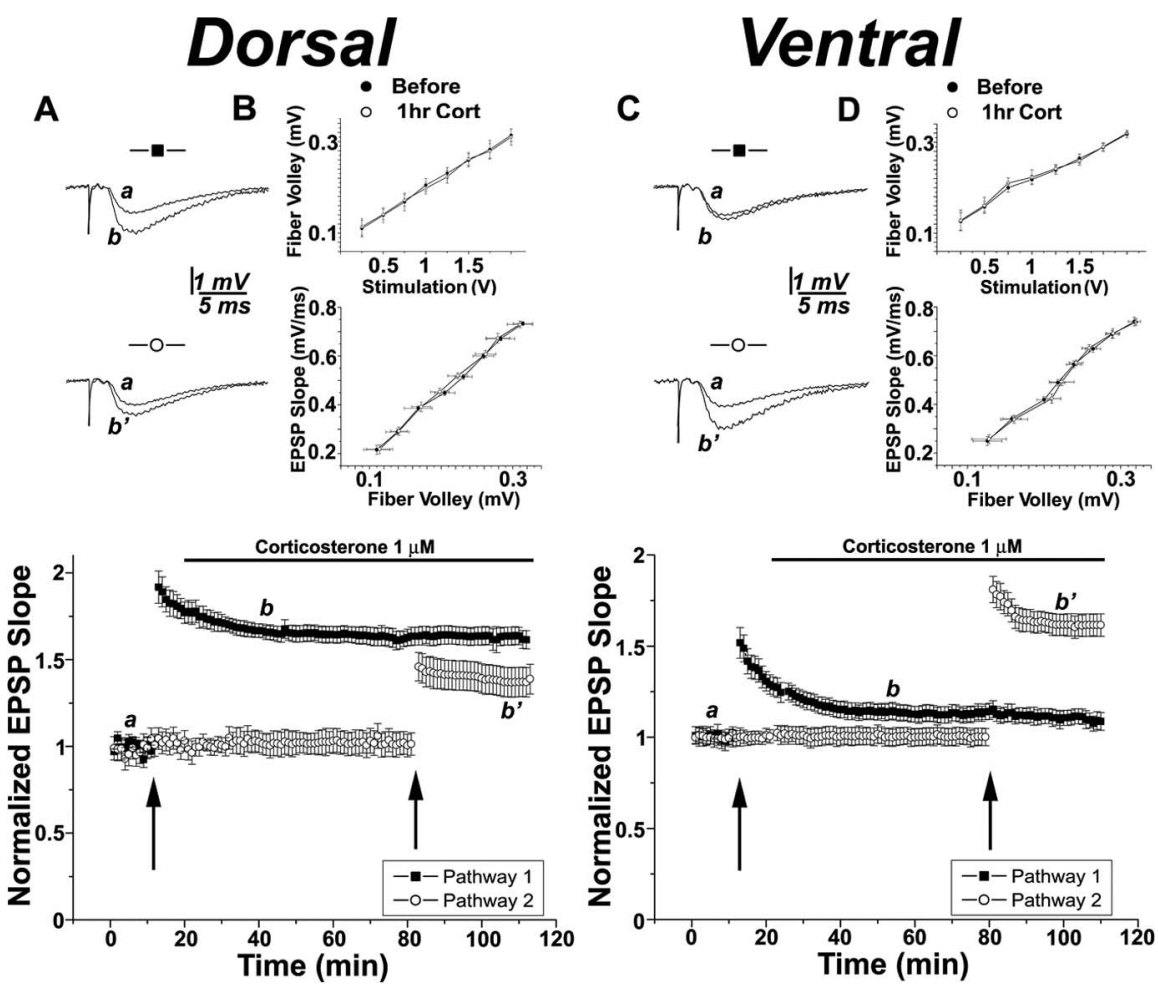

Figure 4. Corticosterone mimics the effects of the behavioral stress in DH and VH slices. A, In DH, corticosterone depresses LTP (open circles) compared with control (filled squares). $\boldsymbol{B}$, Input- output curves do not differ before (filled circles) and after (open circles) corticosterone (Cort) application. C, In VH, corticosterone enhanced LTP (open circles) compared with control (filled squares). $\boldsymbol{D}$, Input- output curves do not differ before (filled circles) and after (open circles) corticosterone application. Averaged EPSP slopes are plotted versus time. Representative traces at indicated times are shown on top. The arrows indicate the times of
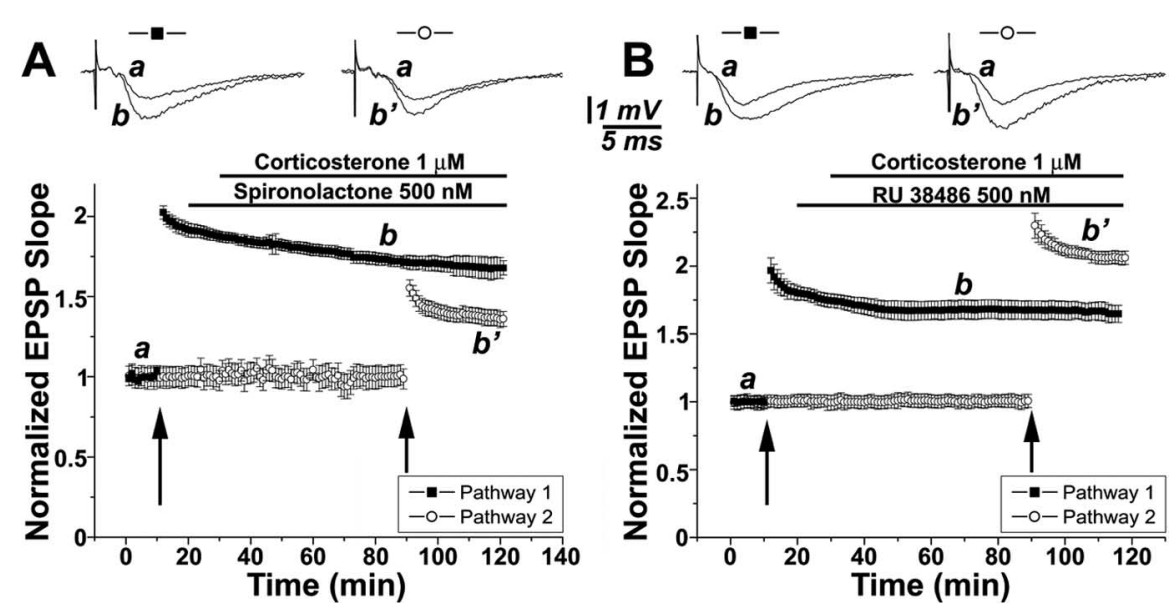

Figure 5. Glucocorticoid receptors mediate the lower-magnitude LTP evoked in dorsal hippocampus after corticosterone application. $\boldsymbol{A}$, Corticosterone in presence of spironolactone ( $500 \mathrm{~nm}$ ) evokes a lower-magnitude LTP (open circles) than in the control pathway (filled squares). $\boldsymbol{B}$, Corticosterone in presence of RU38486 (500 nm) induces an increase in LTP magnitude (open circles) compared with the control pathway (filled squares). Averaged EPSP slopes are plotted versus time. Representative traces at indicated times are shown on top. The arrows indicate the times of HFS.

resulted in a full-magnitude LTP (at $30 \mathrm{~min}$ from the onset, $1.83 \pm 0.032 ; n=9$ ) (Fig. $5 A$ ). However, when an HFS was delivered to the unpotentiated pathway, after exposure to corticosterone in the presence of the specific MR antagonist spironolactone, a lower-magnitude LTP than control was evoked (1.36 \pm $0.046 ; p<0.001 ; n=9$ ) (Fig. $5 A$ ). On the other hand, bath application of corticosterone in presence of the specific GR an- 

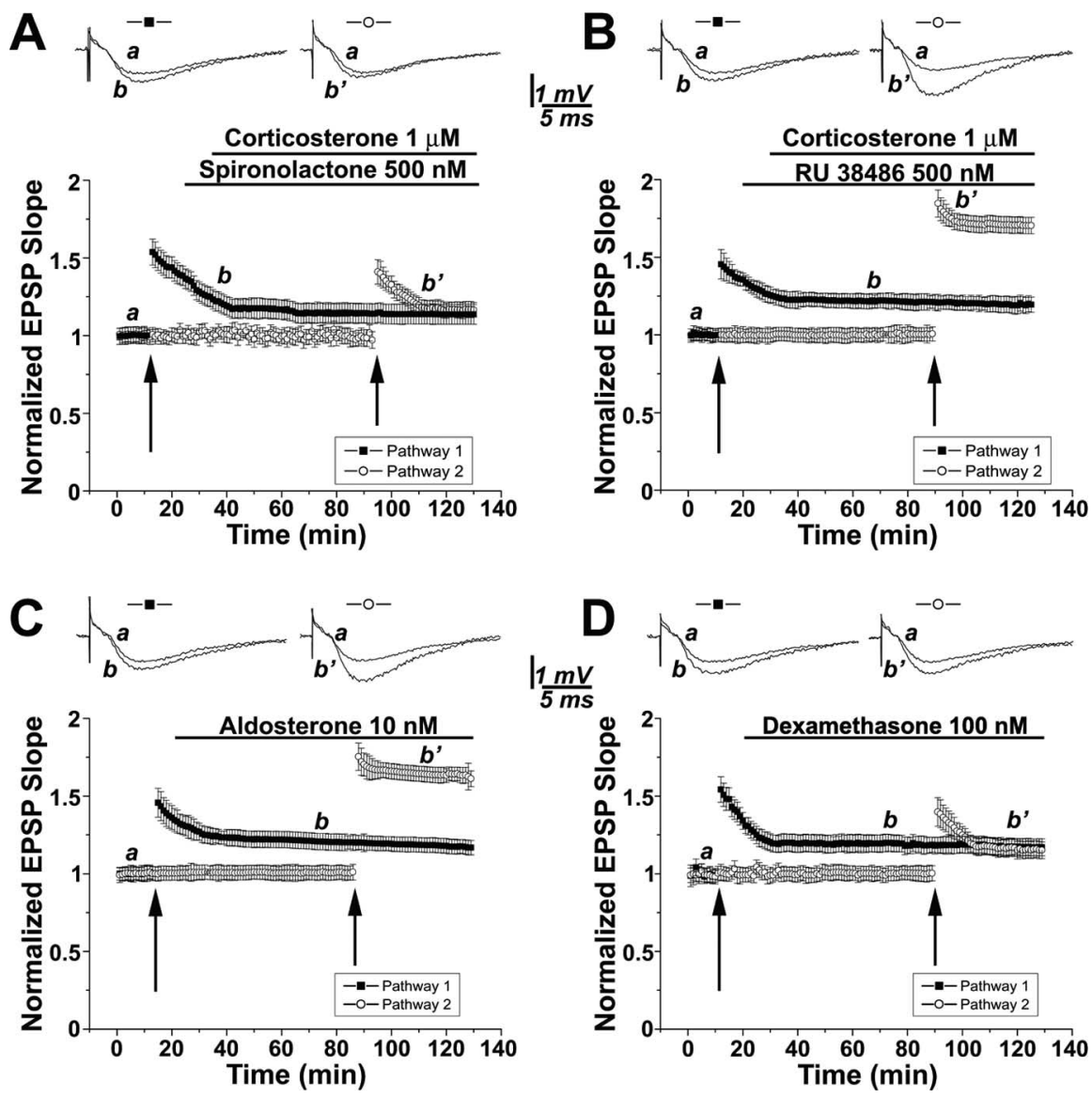

Figure 6. Mineralocorticoid receptors induce LTP facilitation in ventral hippocampal slices. $\boldsymbol{A}$, Corticosterone in presence of spironolactone evokes a slightly lower-magnitude LTP (open circles) than in the control pathway (filled squares). $\boldsymbol{B}$, Corticosterone application in presence of RU38486 (500 nm) induces a higher-magnitude LTP (open circles) than in the control pathway (filled squares). C, Application of the MR agonist aldosterone enhances LTP (open circles) compared with control (filled squares) in ventral hippocampal slices. D, GR agonist dexamethasone (100 nm) induces a lower LTP (open circles) than in control (filled squares). Averaged EPSP slopes are plotted versus time. Representative traces at indicated times are shown on top. The arrows indicate the times of HFS.

tagonist RU38486 evoked a higher-magnitude LTP after HFS than with control no-drug conditions $(2.06 \pm 0.049$ and $1.70 \pm 0.06$, respectively; $p<0.05 ; n=9$ ) (Fig. $5 B$ ). This experiment indicates that GR activation is likely responsible for the lower-magnitude LTP after HFS in the presence of corticosterone in the DH.

The situation was strikingly different in the VH, in which HFS in presence of corticosterone produced a full-fledged LTP (Fig. 4). This enhanced LTP was completely blocked by spironolactone (at $30 \mathrm{~min}$ from the onset, $1.16 \pm 0.05$ compared with $1.17 \pm 0.06$ of the correspondent control pathway; $p=0.087 ; n=9$ ) (Fig. $6 \mathrm{~A}$ ), indicating the involvement of MR in the effect. In contrast, the GR antagonist RU38486 did not block the enhancing action of corticosterone on LTP (at $30 \mathrm{~min}$ from the onset, $1.70 \pm 0.05$ compared with $1.22 \pm 0.04$ of the corresponding control pathway; $p<0.001 ; n=9$ ) (Fig. $6 B$ ), indicating that MRs and not GRs are likely to be activated to produce the enhanced LTP in VH.

To complement these observations, agonists for GRs and MRs were applied to $\mathrm{VH}$ slices, and the resultant effect on ability to produce LTP was evaluated. In the presence of a fairly low concentration of aldosterone (10 nM), an MR agonist perfused for 60 min, HFS produced a large LTP $(1.63 \pm 0.05$ compared with $1.23 \pm 0.05$ of the control pathway; $p<0.001 ; n=9$ ) (Fig. $6 C$ ), as seen with corticosterone itself. However, dexamethasone, a GR agonist, could not mimic this effect and did not produce LTP, as seen before (at 30 min from the onset, $1.15 \pm 0.053 \mathrm{com}$ pared with $1.19 \pm 0.054$ of the control pathway; $p=0.87 ; n=9$ ) (Fig. $6 D)$. Once again, these results support the contention that MRs but not GRs are responsible for the enhanced LTP in the VH.

To verify that the long exposure to the antagonists has no effect of its own, either because of an action on endogenously released steroids or because of an effect on the viability of the slices, the long-term effects of the antagonists were examined in both the $\mathrm{DH}$ and $\mathrm{VH}$. As summarized in Figure 7, neither the MR or GR antagonists had an effect on the ability to produce LTP, even when they were applied for well over $1 \mathrm{~h}$.

Two complementary experiments were conducted to determine the critical time of exposure to the elevated levels of corticosterone in the hippocampus. For these experiments, the rats were stressed in presence or absence of spironolactone, followed by the slice experiments, or were stressed, and only the slices were exposed to this MR antagonist. Briefly, spironolactone was injected subcutaneously (20 mg/ $\mathrm{kg}) 1.5 \mathrm{~h}$ before the exposure to the ASS to allow proper passage of the drug through the blood-brain barrier and its binding to the receptors (Avital et al., 2006). Slices were cut $1 \mathrm{~h}$ after the exposure to stress as usual. Under these conditions, spironolactone blocked the effects of stress on LTP in the VH (Fig. 8A). A two-way ANOVA for mixed design with group as betweensubjects factor and time as within-subjects factor revealed a significant effect for the time of measurement (i.e., 15, 40, or $70 \mathrm{~min} ; F_{(2,27)}=30.84 ; p<$ $0.0001)$. Moreover, a significant difference was found between the groups $\left(F_{(3,28)}=58.97 ; p<0.0001\right)$. A Tukey post hoc test revealed a significant difference between the stressed group and all of the other groups $(p<0.0001)$. This experiment demonstrates that activation of MRs during stress is necessary for later enhancement of LTP in the VH.

The complementary experiment was then conducted: would blockade of MRs in the slices during the induction of LTP counteract the potentiating effect of earlier stress on LTP seen above? We addressed this issue in the experiments summarized in Figure $8 \mathrm{~B}$. Delivery of HFS in presence of spironolactone, in VH slices from animals that were previously exposed to stress, evoked LTP as large as that seen in the previously stressed, undrugged rats $(1.77 \pm 0.05$ compared with $1.70 \pm 0.073 ; p=0.83 ; n=6$ ) (Fig. $8 \mathrm{~B})$. This experiment demonstrates that $\mathrm{VH}$ slices of stressed animals are committed to enhanced LTP already before the HFS was delivered and that subsequent blockade of MR does not block this propensity.

\section{MRs act through VGCCs to enhance LTP in the VH}

MRs have been shown previously to influence synaptic plasticity (Pavlides et al., 1996). Specifically, it has been reported that their 
effect involves calcium influx (Rey et al., 1994). To examine whether MRs enhance the entry of calcium into neurons, their effects on NMDA receptors (NMDARs) and/or VGCCs were studied. The effect of MRs on NMDA receptors was studied in two complementary experiments; in the first (Fig. 9A), 10 min after the HFS to the control pathway, $50 \mu \mathrm{M}$ APV was added to the $\mathrm{VH}$ slices, and aldosterone was applied $10 \mathrm{~min}$ later. After $1 \mathrm{~h}$ of exposure to aldosterone in the presence of APV, HFS was applied to the second pathway. This stimulation led to potentiation $(1.74 \pm 0.074)$ that was higher than that of the control pathway $(1.21 \pm 0.077 ; p<0.001 ; n=9)$. These results indicate that the potentiating effect of aldosterone on LTP is independent of the activation of NMDARs and that in fact, LTP facilitation by the steroid hormone is of a non-NMDA type. To verify the lack of effect of MRs on NMDARs, a second experiment was performed (Fig. $9 B)$ : after 10 min of baseline, the slice was superfused with a modified ACSF that promotes detection of NMDAR EPSPs (containing $0 \mathrm{Mg}^{2+}, 10 \mu \mathrm{M}$ DNQX, and 10 $\mu \mathrm{M}$ glycine). After a stable NMDAmediated EPSP was obtained, aldosterone was added, but it did not affect the NMDA EPSP (EPSP slope, $-0.21 \pm 0.021$ compared with $-0.22 \pm 0.022$ before the drug; $p=$ $0.338 ; n=9)$, indicating that NMDARs are not likely to mediate the effect of aldosterone on LTP in VH.

Calcium ions can permeate the membrane through VGCCs. These channels increase permeability to calcium when the neuronal membrane is depolarized during the EPSP. To test the possibility that MRs activate VGCCs to enhance LTP, a specific L-type VGCCs antagonist, nifedipine (10 $\mu \mathrm{M})$, was used. Nifedipine by itself did not affect EPSPs or the typical low-level LTP in the VH under control conditions (Fig. 10). However, in the presence of nifedipine, aldosterone could no longer potentiate EPSP slope in response to HFS beyond the control level (at $30 \mathrm{~min}$ from the onset level respectively, $1.19 \pm 0.045$ compared with $1.21 \pm 0.043 ; p=0.92 ; n=9)$. This experiment indicates that MRs act through VGCCs to facilitate LTP in the VH.

Corticosteroids are known to exert their effect on the target cell by binding to membrane receptors, from which they are transported into the nucleus to exert specific genomic action. Another, more recently described mechanism involves a direct action on membrane receptors (de Kloet et al., 1996). Specifically, it has been suggested that mitogen-activated protein (MAP) kinases mediate the fast, non-
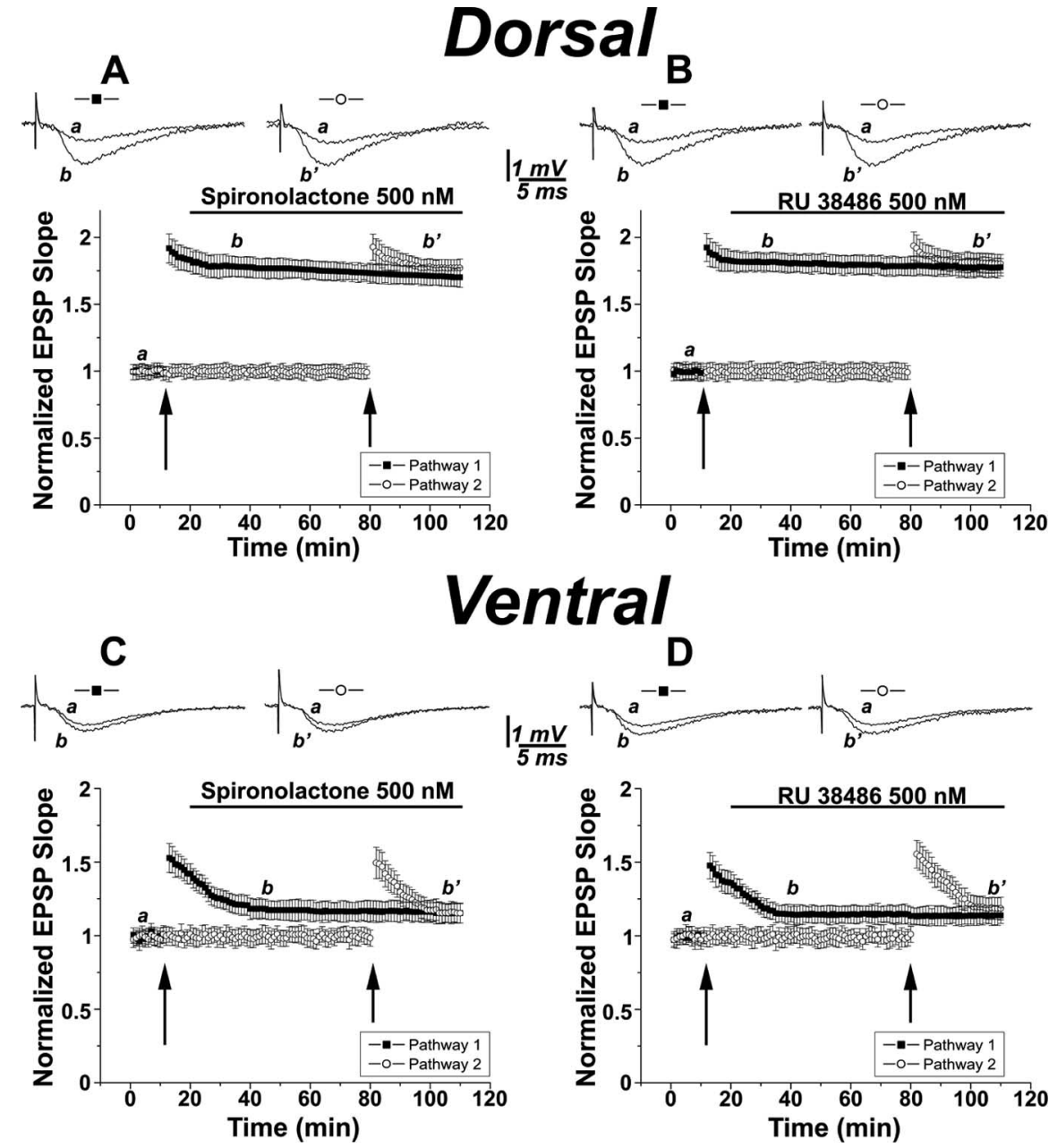

Figure 7. Blockade of MRs and GRs in slices of naive rats and in the absence of corticosterone does not change LTP properties in DH and VH slices. Averaged EPSP slopes are plotted versus time. Representative traces at indicated times are shown on top. The arrows indicate the times of HFS.
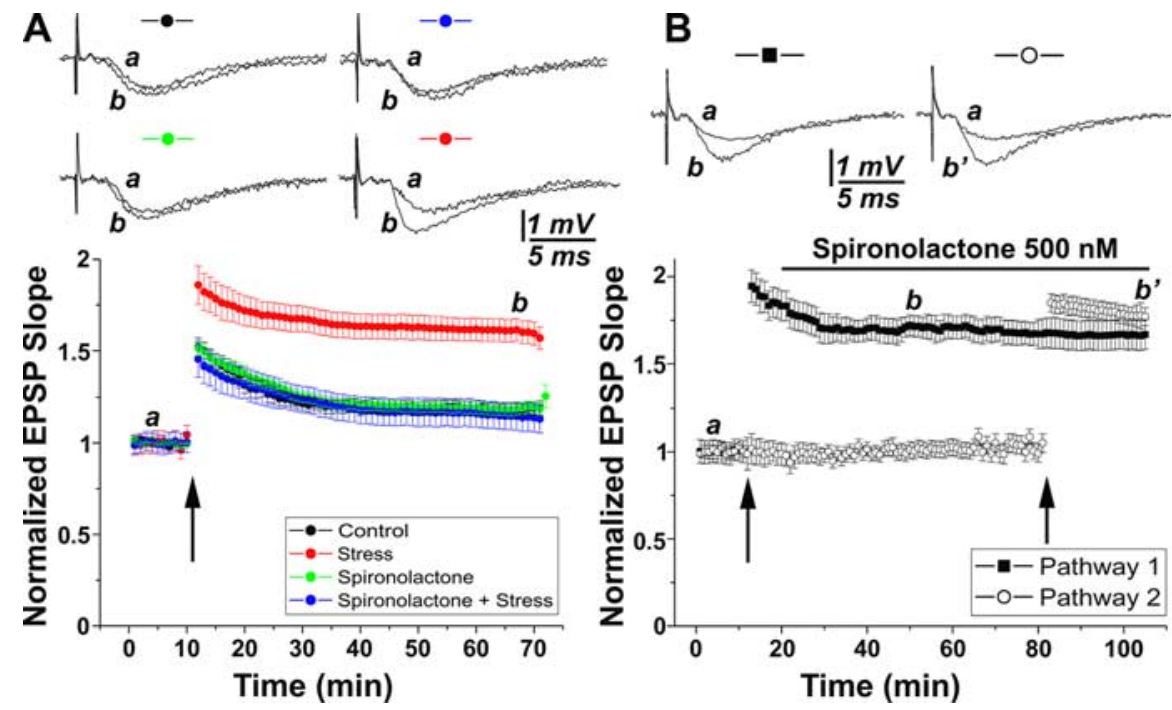

Figure 8. Blockade of MRs during stress blocks LTP in ventral hippocampus. A, LTP enhancement was impaired in VH of animals treated in vivo with spironolactone before stress exposure (blue circles) compared with the group that was only exposed to stress (red circles). $\boldsymbol{B}$, Application of spironolactone to slices of animals previously exposed to stress does not block the enhanced LTP (open circles) compared with the control pathway (filled squares). Averaged EPSP slope is plotted versus time. Representative traces at indicated times are shown on top. The arrows indicate the times of HFS. 


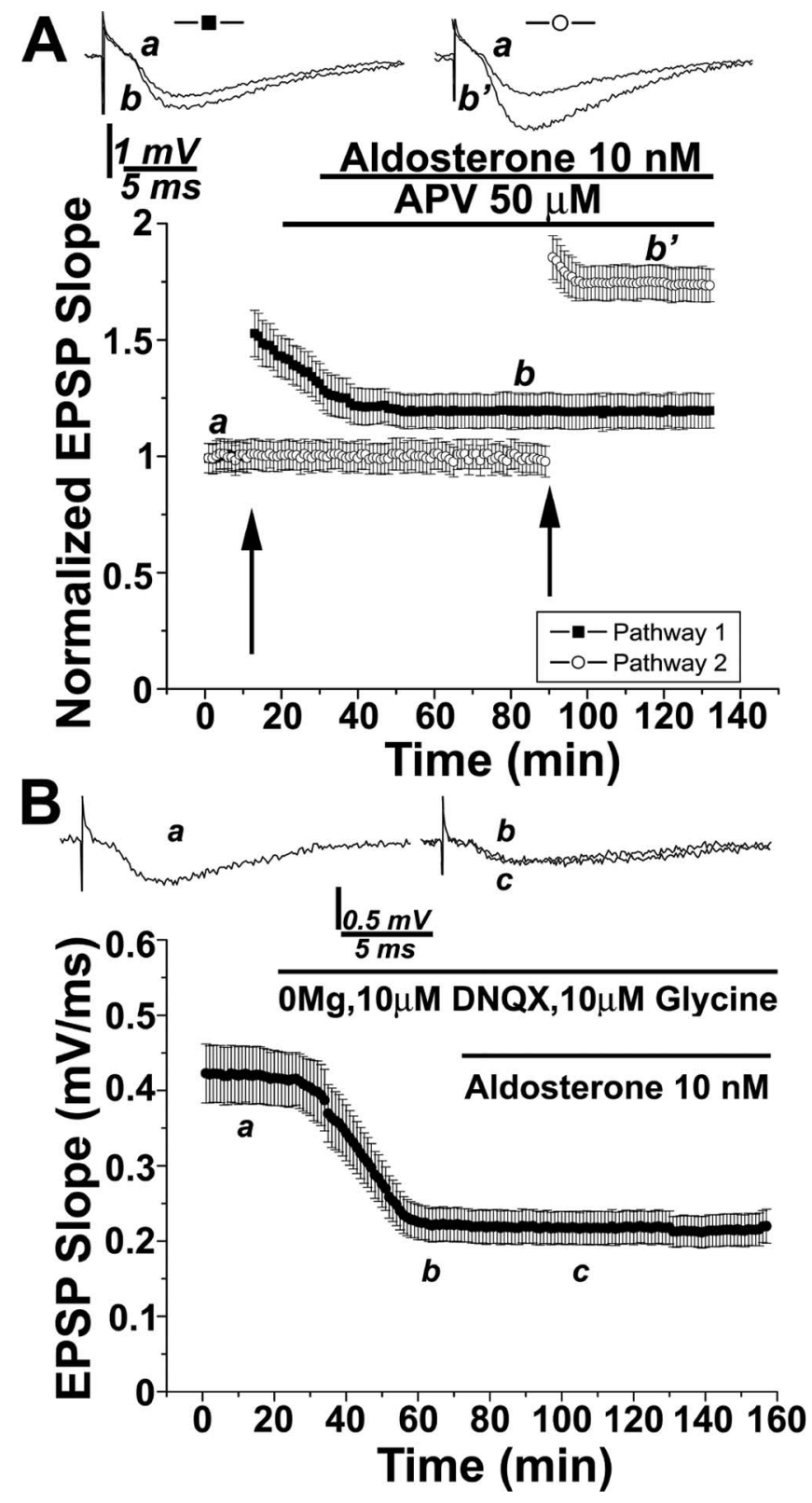

Figure 9. NMDARs are not involved in the MR-mediated LTP in VH. $\boldsymbol{A}$, In the presence of APV, aldosterone induces a higher magnitude of LTP (open circles) than in the control (filled squares). Averaged EPSP slope is plotted versus time. Representative traces at indicated times are shown on top. The arrows indicate the times of HFS. $\boldsymbol{B}$, Aldosterone does not change NMDA receptor function. Hippocampal slices were placed in a perfusion chamber, and EPSPs were recorded in stratum radiatum in response to stimulation. After stable baseline conditions were established, the perfusion medium was changed to magnesium-free ACSF containing glycine and $10 \mu \mathrm{m}$ DNQX. After stable NMDA receptor-mediated EPSPs were established, $10 \mathrm{~nm}$ aldosterone was added to the medium, and EPSPs were recorded. Representative traces at indicated times are shown on top.

genomic response of corticosteroids (Yang et al., 2004). To test whether the effect of aldosterone on LTP in VH could be mediated by a membrane-bound receptor, aldosterone was bath applied together with $1 \mu \mathrm{M}$ PD98059, an extracellular signalregulated protein kinase (Erk) MAP kinase antagonist. Under these conditions, aldosterone failed to enhance LTP after HFS (at $30 \mathrm{~min}$ from the onset level, $1.15 \pm 0.078$ compared with $1.17 \pm$ $0.074 ; p=0.9 ; n=9$ ) (Fig. 11), indicating that the effect of aldosterone may involve activation of Erk.

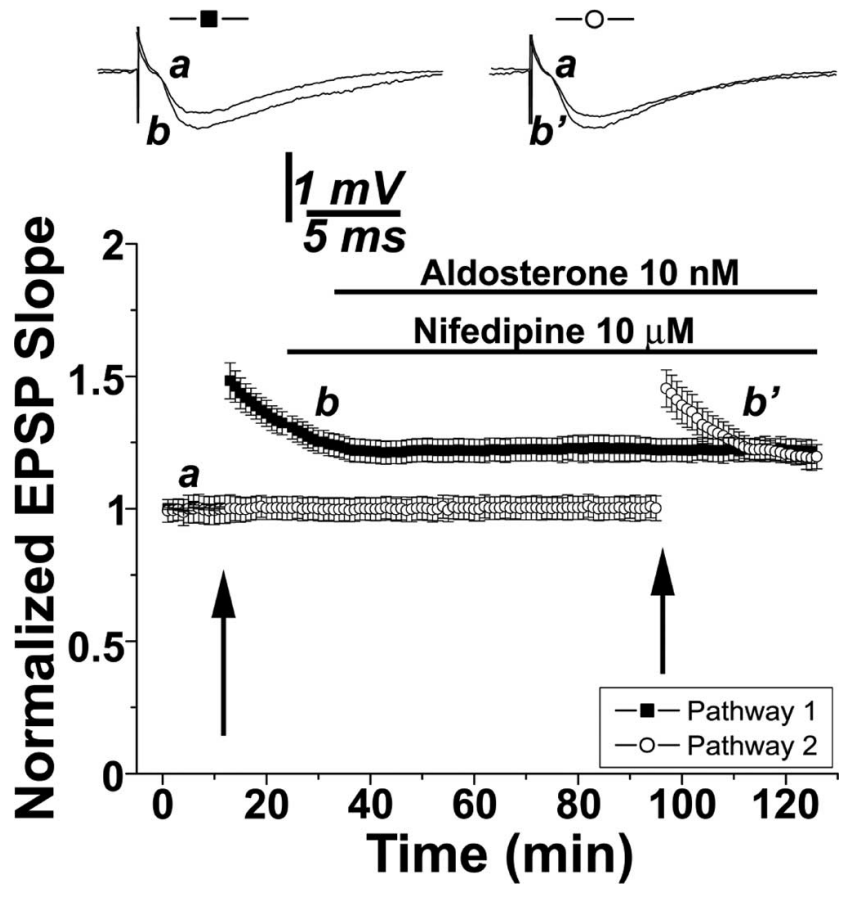

Figure 10. VGCCs mediate the effects of aldosterone in ventral hippocampal slices. In the presence of nifedipine $(10 \mu \mathrm{M})$, aldosterone no longer enhanced LTP but induced a level (open circles) similar to control (filled squares). Averaged EPSP slope is plotted versus time. Representative traces at indicated times are shown on top. The arrows indicate the times of HFS.

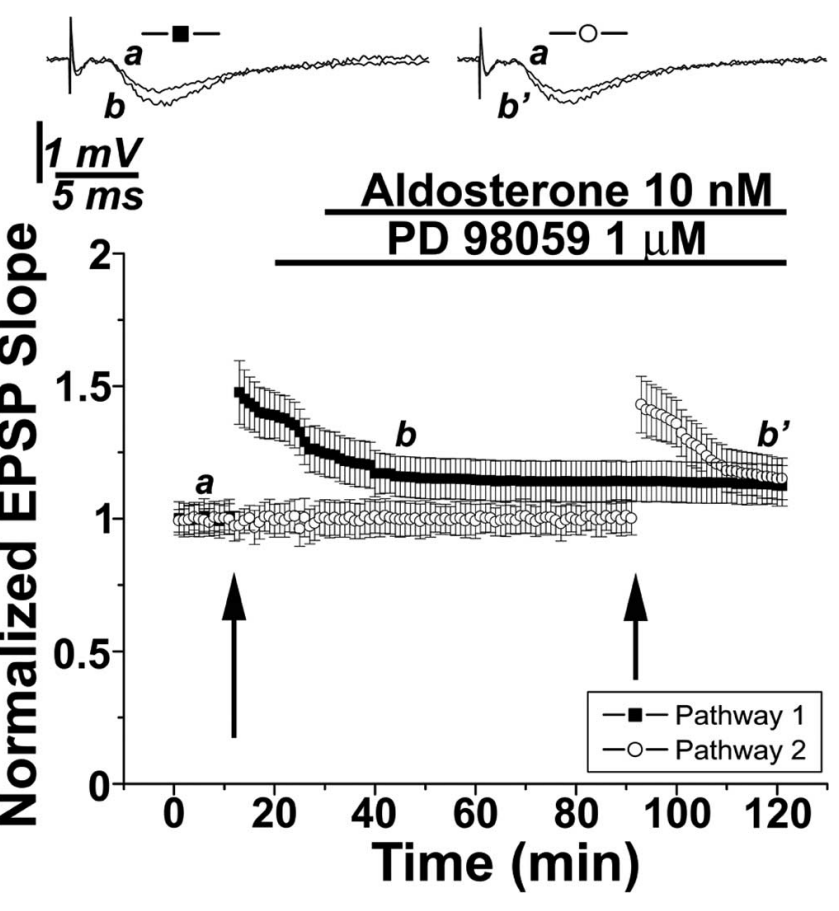

Figure 11. MAP kinases may be involved in the MR-mediated LTP in ventral hippocampus. In the presence of the Erk antagonist (PD98059), aldosterone could no longer cause an enhancement of LTP (open circles) as seen in controls (filled squares). Averaged EPSP slope is plotted versus time. The arrows indicate the time of HFS. Representative traces at indicated times are shown on top.

\section{Discussion}

In the present study, we have shown that the VH CA1 is unable to express as large LTP as sister slices taken from the other sectors along the septotemporal axis of the hippocampus. This deficit is 
not likely to be caused by specific synaptic properties in this region, because the basal synaptic transmission, expressed in the input-output relations, is very similar in the different sectors. Our experiments indicate that it is the dynamic properties of the network, expressed in the ability to undergo LTP, that are unique to the VH. In this respect, the existence of a different local interneuronal network in $\mathrm{VH}$ than in $\mathrm{DH}$ could underlie this altered ability to express LTP, as suggested previously (Papatheodoropoulos and Kostopoulos, 2002), where VH exhibits a unique EEG rhythm that is blocked by $\mathrm{GABA}_{\mathrm{A}}$ agonists. In addition, it has been reported that there is a higher density of calbindin-positive interneurons in VH than in DH (Freund and Buzsaki, 1996).

We have also shown that preexposure to ASS as well as to corticosterone results in suppression of LTP in DH and its emergence in the VH. The reduction of LTP magnitude after stress or corticosterone application has already been described (Alfarez et al., 2002; Yang et al., 2004; Krugers et al., 2005; Wiegert et al., 2005). However, we have now demonstrated that this trend is reversed in the $\mathrm{VH}$. It has been shown both in vivo (Korz and Frey, 2003; Avital et al., 2006) and in vitro (Krugers et al., 2005, 2006; Wiegert et al., 2005) that corticosterone can differentially modulate LTP and synaptic transmission (Karst and Joels, 2005; Karst et al., 2005) by activating different types of receptors. Specifically, it was shown that activation of the high-affinity MRs facilitates LTP after stress (Korz and Frey, 2003; Avital et al., 2006), whereas the low-affinity GRs specifically inhibit NMDAdependent LTP (Wiegert et al., 2005). In our study, corticosterone at a fairly high dose $(1 \mu \mathrm{M})$, which is likely to activate the low-affinity GRs, impaired LTP in the DH, whereas in the VH, it enhanced LTP. This was likely to be mediated by an MRmediated mechanism, because it was shown also with a low dose of corticosterone, after application of aldosterone alone or corticosterone in presence of a GR antagonist. However, activation of GRs did not change the basal level of LTP in the VH, indicating that their contribution to modulation of LTP in VH is not significant. A plausible hypothesis to explain these results could be that a different distribution of MRs and GRs exists in dorsal versus ventral hippocampus. Specifically, more MRs are assumed to be present in the $\mathrm{VH}$, whereas the $\mathrm{DH}$ is likely to contain more GRs. Accordingly, a high dose of corticosterone should activate more easily GRs in dorsal, whereas MRs should be activated in VH at the same concentration. This hypothesis is supported by a recent study (Robertson et al., 2005), which reports that in a normal animal not exposed to stress, the basal level of MRs in $\mathrm{VH}$ is double that of the $\mathrm{DH}$, whereas the basal level of GRs is twice as high in $\mathrm{DH}$ as in $\mathrm{VH}$.

We found that aldosterone facilitates LTP in VH through a mechanism that requires activation of VGCCs. Our results concur with previous reports on the effects of aldosterone on LTP in CA1 (Pavlides et al., 1996). However, a direct link between aldosterone and activation of L-type calcium channels has not been reported so far. On the contrary, VGCC LTP, which is assumed to be mediated by L-type channels, has been shown to be enhanced by GRs (Krugers et al., 2005). In peripheral tissue, MRs activate T-type rather than L-type calcium channels (Rossier et al., 2003), which are proposed to underlie VGCC LTP. In another study (Rey et al., 1994), it was shown that a low dose of corticosterone, which is assumed to activate primarily MRs, caused an increase in LTP in CA1 only if the extracellular calcium concentration is increased from 2.5 to $3.1 \mathrm{~mm}$. This effect could be mimicked by the presence of high doses of corticosterone together with a specific GR antagonist. In our own study, nifedipine at low concentration, which blocks selectively L-type channels, blocked the ef- fects of MRs in VH. The marked difference between the distributions of MRs and GRs in $\mathrm{DH}$ and $\mathrm{VH}$, as well as the likelihood that different types of MRs (Pascual-Le Tallec and Lombes, 2005) exist in different parts of the hippocampus, leaves this issue of a possible effect of MRs on L-type, VGCC-mediated LTP still open for additional exploration.

It has been reported that corticosteroids have two types of responses: a genomic and a nongenomic (de Kloet et al., 1996; Smythe et al., 1997; Yamada et al., 2003; Karst and Joels, 2005; Karst et al., 2005). The first one is mediated by intracellular corticosteroid receptors, requires protein synthesis, and is thought to be a slower response. The second one is mediated by membrane-bound receptors, does not require protein synthesis, and is considered to be a faster response. On the one hand, in our experiments, the MR antagonist could not block the LTP enhancement mediated by stress, if present only during induction of LTP, indicating a possible involvement of a nongenomic mechanism. On the other hand, in a different series of experiments, aldosterone-promoted LTP was blocked by an Erk antagonist, indicating the involvement of a membrane receptor, because it has been reported that MAP kinases mediate fast corticosterone membrane-bound receptor induced signaling (Yang et al., 2004; Chai et al., 2005).

In conclusion, we have demonstrated that stress and corticosteroids differentially modulate LTP along the septotemporal axis of the hippocampus. It has been shown that blocking MRs (Smythe et al., 1997) lowers anxiety levels in vivo. However, we have shown that MRs are specifically activated in the ventral hippocampus after stress to enable LTP. Altogether, these experiments suggest that MR modulation of synaptic transmission in $\mathrm{VH}$ plays an important role in the functionality of the $\mathrm{VH}$ in situations that challenge the homeostatic balance of the animal. The unique efferents of the $\mathrm{VH}$, connecting the hippocampus to the anterior and medial parts of the hypothalamus and the ventral striatum (Witter and Amaral, 2004), hint at the possible roles of the altered plasticity of the $\mathrm{VH}$ in the ability of the animal to cope with an acute stress.

\section{References}

Ahmed T, Frey JU, Korz V (2006) Long-term effects of brief acute stress on cellular signaling and hippocampal LTP. J Neurosci 26:3951-3958.

Alfarez DN, Wiegert O, Joels M, Krugers HJ (2002) Corticosterone and stress reduce synaptic potentiation in mouse hippocampal slices with mild stimulation. Neuroscience 115:1119-1126.

Anderson WW, Collingridge GL (2001) The LTP Program: a data acquisition program for on-line analysis of long-term potentiation and other synaptic events. J Neurosci Methods 108:71-83.

Avital A, Segal M, Richter-Levin G (2006) Contrasting roles of corticosteroid receptors in hippocampal plasticity. J Neurosci 26:9130-9134.

Bannerman DM, Yee BK, Good MA, Heupel MJ, Iversen SD, Rawlins JN (1999) Double dissociation of function within the hippocampus: a comparison of dorsal, ventral, and complete hippocampal cytotoxic lesions. Behav Neurosci 113:1170-1188.

Bannerman DM, Grubb M, Deacon RM, Yee BK, Feldon J, Rawlins JN (2003) Ventral hippocampal lesions affect anxiety but not spatial learning. Behav Brain Res 139:197-213.

Bannerman DM, Rawlins JN, McHugh SB, Deacon RM, Yee BK, Bast T, Zhang WN, Pothuizen HH, Feldon J (2004) Regional dissociations within the hippocampus-memory and anxiety. Neurosci Biobehav Rev 28:273-283.

Bliss TV, Collingridge GL (1993) A synaptic model of memory: long-term potentiation in the hippocampus. Nature 361:31-39.

Chai W, Garrelds IM, de Vries R, Batenburg WW, van Kats JP, Danser AH (2005) Nongenomic effects of aldosterone in the human heart: interaction with angiotensin II. Hypertension 46:701-706.

Colgin LL, Kubota D, Jia Y, Rex CS, Lynch G (2004) Long-term potentiation 
is impaired in rat hippocampal slices that produce spontaneous sharp waves. J Physiol (Lond) 558:953-961.

Colombo M, Fernandez T, Nakamura K, Gross CG (1998) Functional differentiation along the anterior-posterior axis of the hippocampus in monkeys. J Neurophysiol 80:1002-1005.

Degroot A, Treit D (2004) Anxiety is functionally segregated within the septo-hippocampal system. Brain Res 1001:60-71.

de Kloet ER, Rots NY, Cools AR (1996) Brain-corticosteroid hormone dialogue: slow and persistent. Cell Mol Neurobiol 16:345-356.

Finn DP, Martí O, Harbuz MS, Vallès A, Belda X, Márquez C, Jessop DS, Lalies MD, Armario A, Nutt DJ, Hudson AL (2003) Behavioral, neuroendocrine and neurochemical effects of the imidazoline I2 receptor selective ligand BU224 in naive rats and rats exposed to the stress of the forced swim test. Psychopharmacology (Berl) 167:195-202.

Freund T, Buzsaki G (1996) Interneurons of the hippocampus. Hippocampus 6:347-470.

Garcia R (2002) Stress, metaplasticity, and antidepressants. Curr Mol Med 2:629-638.

Joels M (2006) Corticosteroid effects in the brain: U-shape it. Trends Pharmacol Sci 27:244-250.

Karst H, Joels M (2005) Corticosterone slowly enhances miniature excitatory postsynaptic current amplitude in mice CA1 hippocampal cells. J Neurophysiol 94:3479-3486.

Karst H, Berger S, Turiault M, Tronche F, Schutz G, Joels M (2005) Mineralocorticoid receptors are indispensable for nongenomic modulation of hippocampal glutamate transmission by corticosterone. Proc Natl Acad Sci USA 102:19204-19207.

Kim JJ, Yoon KS (1998) Stress: metaplastic effects in the hippocampus. Trends Neurosci 21:505-509.

Kim JJ, Song EY, Kosten TA (2006) Stress effects in the hippocampus: synaptic plasticity and memory. Stress 9:1-11.

Kjelstrup KG, Tuvnes FA, Steffenach HA, Murison R, Moser EI, Moser MB (2002) Reduced fear expression after lesions of the ventral hippocampus. Proc Natl Acad Sci USA 99:10825-10830.

Korz V, Frey JU (2003) Stress-related modulation of hippocampal longterm potentiation in rats: involvement of adrenal steroid receptors. J Neurosci 23:7281-7287.

Krugers HJ, Alfarez DN, Karst H, Parashkouhi K, van Gemert N, Joels M (2005) Corticosterone shifts different forms of synaptic potentiation in opposite directions. Hippocampus 15:697-703.

Krugers HJ, Goltstein PM, van der Linden S, Joels M (2006) Blockade of glucocorticoid receptors rapidly restores hippocampal CA1 synaptic plasticity after exposure to chronic stress. Eur J Neurosci 23:3051-3055.

Maggio N, Segal M (2007) Unique regulation of long term potentiation in the rat ventral hippocampus. Hippocampus 17:10-25.

Maruki K, Izaki Y, Nomura M, Yamauchi T (2001) Differences in pairedpulse facilitation and long-term potentiation between dorsal and ventral CA1 regions in anesthetized rats. Hippocampus 11:655-661.

Moser MB, Moser EI (1998) Functional differentiation in the hippocampus. Hippocampus 8:608-619.
Papatheodoropoulos C, Kostopoulos G (2000) Decreased ability of rat temporal hippocampal CA1 region to produce long-term potentiation. Neurosci Lett 279:177-180.

Papatheodoropoulos C, Kostopoulos G (2002) Spontaneous GABA(A) dependent synchronous periodic activity in adult rat ventral hippocampal slices. Neurosci Lett 319:17-20.

Pascual-Le Tallec L, Lombes M (2005) The mineralocorticoid receptor: a journey exploring its diversity and specificity of action. Mol Endocrinology 19:2211-2221.

Pavlides C, Ogawa S, Kimura A, McEwen BS (1996) Role of adrenal steroid mineralocorticoid and glucocorticoid receptors in long-term potentiation in the CA1 field of hippocampal slices. Brain Res 738:229-235.

Pothuizen HH, Zhang WN, Jongen-Relo AL, Feldon J, Yee BK (2004) Dissociation of function between the dorsal and the ventral hippocampus in spatial learning abilities of the rat: a within-subject, within-task comparison of reference and working spatial memory. Eur J Neurosci 19:705-712.

Rey M, Carlier E, Talmi M, Soumireu-Mourat B (1994) Corticosterone effects on long-term potentiation in mouse hippocampal slices. Neuroendocrinology 60:36-41.

Robertson DA, Beattie JE, Reid IC, Balfour DJ (2005) Regulation of corticosteroid receptors in the rat brain: the role of serotonin and stress. Eur J Neurosci 21:1511-1520.

Rossier MF, Lesouhaitier O, Perrier E, Bockhorn L, Chiappe A, Lalevee N (2003) Aldosterone regulation of T-type calcium channels. J Steroid Biochem Mol Biol 85:383-388.

Smythe JW, Murphy D, Timothy C, Costall B (1997) Hippocampal mineralocorticoid, but not glucocorticoid, receptors modulate anxiety-like behavior in rats. Pharmacol Biochem Behav 56:507-513.

Strange BA, Fletcher PC, Henson RN, Friston KJ, Dolan RJ (1999) Segregating the functions of human hippocampus. Proc Natl Acad Sci USA 96:4034-4039.

Trivedi MA, Coover GD (2004) Lesions of the ventral hippocampus, but not the dorsal hippocampus, impair conditioned fear expression and inhibitory avoidance on the elevated T-maze. Neurobiol Learn Mem 81:172-184.

Wiegert O, Pu Z, Shor S, Joels M, Krugers H (2005) Glucocorticoid receptor activation selectively hampers $N$-methyl-D-aspartate receptor dependent hippocampal synaptic plasticity in vitro. Neuroscience 135:403-411.

Witter MP, Amaral DG (2004) Hippocampal formation. In: The rat nervous system, Ed 3 (Paxinos G, ed), pp 635-693. Academic.

Yamada K, McEwen BS, Pavlides C (2003) Site and time dependent effects of acute stress on hippocampal long-term potentiation in freely behaving rats. Exp Brain Res 152:52-59.

Yang CH, Huang CC, Hsu KS (2004) Behavioral stress modifies hippocampal synaptic plasticity through corticosterone-induced sustained extracellular signal-regulated kinase/mitogen-activated protein kinase activation. J Neurosci 24:11029-11034. 